\title{
El servicio civil en la China imperial
}

\author{
OMAR Martínez LegorretA*
}

\begin{abstract}
This article describes the beginnings of the Chinese Empire and its government structure: the bureaucracy of learned-public officials (Mandarins), a class with a small number of people that had all the power and was the major owner of great areas of land. These officials were in charge of all the administration and mediation functions. They were trained and indoctrinated according to the principles of Confucianism and had a strategic position from which they could influence the rest of the government policies and assured their permanence. In that way, a lifetime career civil service was established, that had the tasks of governing and administering, and at the same time provided to the Imperial regime with the rational approval and ethics needed for the exercise of authority. The secret of its continuity and survival consisted of the system of examinations to recruit officials for the State.
\end{abstract}

Keywords: learned-public officials, Confucianism, Imperial civil service, system of examinations for admission, Imperial restoration.

\section{Resumen}

El texto describe la concepción del imperio chino y la estructura de gobierno que lo sostenía: la burocracia de los eruditos-funcionarios (mandarines), una clase numéricamente pequeña que ostentaba todo el poder y era la mayor propietaria de grandes extensiones de tierra. Todas las funciones de administración y mediación estaban a cargo de esos funcionarios, quienes eran preparados según los principios filosóficos del confucianismo y ocuparon una posición estratégica desde la que influían en toda política del gobierno y aseguraban así su permanencia. De ese modo se estableció un servicio civil de carrera de por vida, que a la vez que gobernaba y administraba, daba al régimen imperial la sanción racional y ética que necesitaba para el ejercicio de su autoridad. El secreto de su continuidad y supervivencia estaba en el sistema de exámenes para reclutar funcionarios para el Estado.

Palabras clave: eruditos-funcionarios, confucianismo, servicio civil imperial, sistema de exámenes de ingreso, Restauración imperial.

*El Colegio Mexiquense A.C. Correo-e: omartin@cmq.edu.mx. 


\section{Introducción}

Durante el primer periodo de unificación del imperio chino (221207 a.C.) el vasto imperio que resultó se puso bajo una sola administración, como correspondía a un Estado centralizado. La concepción del imperio y la estructura de gobierno que lo sostenía se armó con base en una filosofía que sancionó el gobierno y la articulación paulatina de una clase social que resultó indispensable: la de los eruditos-funcionarios (mandarines), numéricamente pequeña, pero que ejercía todo el poder y era la propietaria principal de grandes extensiones de tierra. Las funciones de administración y mediación estaban a cargo de esos eruditosfuncionarios, quienes eran a la vez arquitectos, ingenieros, maestros, administradores y gobernantes; esas tareas constituían la profesión de gobernar. Para funcionar también como consejeros, estos personajes eran indoctrinados y preparados según los principios de la filosofía oficial, el confucianismo, y desde la posición estratégica que ocuparon podían influir en la política del gobierno a la vez que aseguraban su permanencia. De ese modo se estableció un servicio civil de carrera de por vida, que a la vez que gobernaba y administraba, daba al régimen imperial la sanción racional y ética que necesitaba para el ejercicio de su autoridad. El secreto de su continuidad y supervivencia estaba en el sistema de exámenes únicos y competitivos para reclutar funcionarios para el Estado.

Primeramente, este artículo describe la sociedad china antigua y la instalación del imperio como trasfondo para el surgimiento de la burocracia. En una segunda parte se describen los principios confucianistas normativos del mandarinato; en la tercera, se considera el sistema de exámenes del servicio civil y si constituyeron una oportunidad abierta al talento personal. La cuarta parte menciona el neoconfucianismo como base de la Restauración T'ung-Chih, el último intento de volver al pasado para detener el desmoronamiento del imperio y hacer frente al asedio del exterior. Las conclusiones recapitulan la experiencia china con su servicio civil de carrera y mencionan los esfuerzos de la República Popular China que necesita instaurar un servicio civil nuevo con el que pueda hacer frente a este nuevo periodo de su historia. 


\section{La sociedad china antigua}

Cuando el primer emperador de la dinastía Ch'in unificó el imperio chino (221-207 a.C.) se trazaron las líneas generales de la institución imperial y del sistema de gobierno que seguirían las dinastías posteriores para gobernar aquel vasto imperio. Aun cuando el reinado de la dinastía Ch'in fue breve, por primera vez el país se puso bajo una sola administración, un Estado centralizado que tenía poder sin precedentes, controlaba grandes recursos y desplegaba tal magnificencia que inspiraba a la vez un sentimiento de respeto y temor a sus habitantes y al exterior.

Al desaparecer, la dinastía Ch'in dejó como legado más importante a la dinastía Han que le sucedió (202 a.C.-220 d.C.) la concepción del imperio y la estructura de gobierno que lo sostenía. Durante los cuatro siglos que duró esa dinastía -un largo periodo de consolidación-, se moldearon todos los aspectos de la vida china, incluso los de la esfera intelectual, que perduraron hasta la época moderna no sólo en China, sino también en Corea, Vietnam y aun en Japón.

China era una gran sociedad agraria, muy desarrollada, preindustrial, no marítima, basada en una economía campesina, utilizaba técnicas tradicionales y estaba situada en un subcontinente que carece de articulación geográfica definida. Las familias campesinas constituían la vasta mayoría de la población, esparcidas sobre un inmenso territorio comunicado principalmente por una red de canales, que vivían en autarquía económica. Se bastaban a sí mismas, pero con un sistema de intercambios económicos que, si no hubieran tenido un marco de organización impuesto desde arriba, se habrían desintegrado.

Esa sociedad era burocrática porque la pirámide social -que descansaba sobre una amplia base campesina y cuyos estratos intermedios estaban constituidos por una clase de mercaderes y otra de artesanos, que eran pocos, carecían de autonomía, tenían una posición inferior y no eran respetadas- estaba coronada y caracterizada por su cúspide: el mandarinato.

La clase de los eruditos-funcionarios (o mandarines), que era numéricamente pequeña, pero omnipotente a causa de su fuerza, influencia, posición y prestigio, ejercía el poder y poseía la mayor extensión de tierra. Esa clase tenía todos los privilegios, en especial el de reproducirse, porque se fundaba en el monopolio de la educación. Esa élite improductiva derivaba su fuerza de la labor que desempeñaba, la función socialmente necesaria e 
indispensable de coordinar y supervisar el trabajo productivo de otros a fin de hacer funcionar todo el organismo social. Todas las tareas de administración y mediación estaban a cargo de los eruditos-funcionarios. Ellos confeccionaban el calendario, organizaban el transporte y el intercambio, supervisaban la construcción de caminos, canales, diques, represas, y estaban a cargo de todas las obras públicas, especialmente aquellas destinadas a prevenir las sequías e inundaciones; construían las reservas contra el hambre y alentaban todo tipo de proyectos de irrigación. Eran arquitectos, ingenieros, maestros, administradores y gobernantes a un mismo tiempo. Sin embargo, estaban en contra de toda clase de especialización. Solamente reconocían una profesión: la de gobernar.

Por su especialidad en el manejo de las personas y su experiencia en el arte político de gobernar, los eruditos-funcionarios eran la esencia del Estado, que estaba erigido a imagen de ellos: jerárquico y autoritario, paternal aunque tiránico, que se ocupaba del bienestar en forma absolutista; en suma, un Estado totalitario: ejercía un control completo sobre todas las actividades de la vida social y un dominio absoluto en todos los niveles. El Estado chino era reglamentador e intervencionista a tal grado que contra esa característica se levantaba el constante llamamiento del taoismo, que se oponía a la intervención estatal. Nada escapaba a la reglamentación oficial. El comercio, la minería, las construcciones, los ritos, la música, las escuelas y, en realidad, toda la vida pública y gran parte de la vida privada estaban bajo su dominio.

Como en un Estado totalitario, prevalecía una atmósfera de policía secreta y sospechas mutuas que hacían que todos se vigilaran entre sí. Estaba también el carácter arbitrario de la justicia. A los ojos de la autoridad todo acusado se suponía culpable. El terror descansaba sobre el principio de la responsabilidad colectiva (pao-chia), que ponía a temblar a todos los súbditos, y más que nada a los propios eruditos-funcionarios, ya que aunque gobernaban el Estado, también eran sus servidores. Como en toda sociedad totalitaria, las razones de Estado tienen prioridad sobre los derechos humanos, por ello los eruditos-funcionarios, en su calidad de representantes del Estado, eran intocables, pero en lo individual eran nada.

En ese Estado totalitario la tendencia era eliminar de inmediato toda forma de empresa privada, y si no lo lograban, trataban de detenerla a tiempo apoderándose de esa iniciativa o empresa y nacionalizándola. En el curso de la historia china, los 
eruditos-funcionarios, que eran hostiles a todas las invenciones, se apoderaron de los frutos de la inventiva de otros. Tres ejemplos que tuvieron ese destino fueron el papel, inventado por un eunuco; la imprenta, utilizada por los budistas como medio para la propaganda religiosa, y la letra de cambio, un recurso de los empresarios privados.

Otro aspecto del Estado burocrático era el miedo a asumir responsabilidades. La principal preocupación del burócrata chino era evitar todo tipo de compromiso, y siempre se las arreglaba para delegar sus responsabilidades en algún subordinado que pudiera servir de chivo expiatorio si llegaba el caso (Balasz, 1966).

En la síntesis que los intelectuales del imperio Han formularon, lo más importante fue el concepto básico de que el cielo, la tierra y el hombre formaban una tríada eterna. El deber primordial del hombre y su obligación era estudiar y comprender las leyes del cielo, tanto en su sentido religioso como físico. Con la misma convicción decían que el hombre, y especialmente el gobierno -lo que era comprensible en una sociedad agraria- debían atender siempre los asuntos relacionados con la tierra, en especial los que atañían a la irrigación, su uso, control de inundaciones, etc. Los sabios Han insistían en que el bienestar económico era la base de la moralidad popular. Si un estudioso podía comprender los valores morales que le daba la educación, es decir, el aprendizaje, no podía esperarse que la gente común tuviera los mismos valores. Lo que la gente deseaba era tener riqueza y bienestar, y si no podía obtenerlos por medios honestos, los buscarían por otros. Por lo tanto, el deber del gobernante debía ser procurar que la gente obtuviera lo que necesitaba para vivir por medios honestos. El camino a la riqueza y a la virtud debía ser el mismo. Por esa razón, el gobierno y el emperador mismo eran responsables de la conducta moral del pueblo. Si un hombre pobre robaba, era porque no podía vivir honestamente. Ese hombre no era culpable de su situación, sino los sistemas económico y social, por lo tanto, eventualmente, la culpa era del emperador. Si éste rectificaba sus errores, entonces transformaría a su gente y le facilitaría ser virtuosa.

Aquellos fueron los principios de un sistema filosófico, el confucianismo, que se adoptó entonces. Esa filosofía insistía en el deber del gobernante de transformar o llevar a su plenitud la naturaleza del pueblo, o sea, civilizarlo. En ese proceso el primer paso era ver que hubiera paz y prosperidad; el segundo, era el entrenamiento moral o educación, el cual se obtenía mediante 
los ritos, desde las ceremonias religiosas más solemnes hasta las costumbres de la educación diaria, la música y la literatura. Los ritos y la música podían ser apreciados por toda la gente, mientras que la literatura, como era un estudio largo y difícil, sólo podían adquirirla y apreciarla los hombres inteligentes y ociosos, en tanto que no estaban dedicados a la agricultura. El producto final de todo ese proceso era el sabio, el hombre bien educado, quien, por sus conocimientos, poseía el sentido moral más agudo y refinado posible. Idealmente, ese hombre debía ser elegido para emperador, pero como ello causaría un cambio frecuente de gobernantes, lo que llevaría al caos y serían muy grandes las dificultades para elegir sucesores, en la práctica se aceptó el principio dinástico de la sucesión hereditaria, y los sabios o letrados ocuparon la posición de consejeros del emperador. Es decir, el lugar del erudito y sabio estaba en el servicio del gobierno. Operaba por medio de la maquinaria establecida por éste, que supervisaba el bienestar económico, social y espiritual de la nación.

Aliándose con el sistema imperial de la dinastía Han, los eruditos tuvieron varios éxitos significativos: lograron que el confucianismo fuera declarado filosofía oficial del Estado, la fundación de una universidad estatal, un sistema de exámenes competitivos y, en tiempos de paz, ocupar la posición socialmente dominante.

El concepto del Estado y de la función del gobernante, que abarcaba todos los aspectos de la vida de la nación y su gente, expresado en los términos más elevados, fue uno de los mayores logros del pensamiento chino. Los teóricos políticos de la época Han, para dejar en claro el rechazo total a las experiencias y teoría de la dinastía Ch'in de la centralización del poder autocrático y total del emperador, rodearon con habilidad la persona imperial con un aura de misterio divino e insistieron en que el gobernante no debía molestarse en tomar decisiones específicas o llevar a cabo actos de gobierno, sino dejar esas cuestiones en manos de sus ministros quienes, al menos en teoría, habían sido seleccionados con base en su virtud y habilidades personales. En esa forma esperaban evitar cualquier modo de 'culto al individuo' (o a la personalidad). En apoyo de esa teoría, enfatizaban la importancia de la perdurabilidad y flexibilidad del gobierno. El emperador, situado en la cumbre de la gran pirámide, podía permanecer inflexiblemente fiel a ciertos principios de gobierno; pero en los procesos de cada día, la formulación y práctica de 
medidas específicas debían llevarlas a cabo los funcionarios que conocían personalmente la situación.

Esa interpretación de los deberes de los gobernantes, por la cual los elevaban para que hubiera mayor libertad y autoridad de sus ministros, hizo mucho para limitar el poder absoluto del gobernante y evitó así que, por medio del derecho hereditario de sucesión dinástica, llegara a ocupar el trono un dirigente malévolo o incompetente y el gobierno de la nación fuera víctima de sus caprichos. Esto, como en toda teoría política, no siempre se cumplió.

En realidad no siempre se esperaba que el emperador fuera una figura pasiva sentada en el vértice de un gobierno en el cual sus funcionarios ejercían el poder real. Se pensaba que también debía tener un interés personal en la dirección de la vida de la nación. En la concepción de los filósofos Han, el emperador era mucho más que el funcionario principal de una organización burocrática. Era el representante viviente de todo el orden jerárquico de los seres humanos y él mismo era un reflejo del orden mayor del universo. Puesto que el cielo, la tierra y el hombre en el pensamiento chino formaban una tríada inseparable, así el emperador, como cabeza del tercer miembro, era responsable de mantener al género humano en armonía con los otros miembros y, por el poder de su oficio, conducirlo hasta lograr el cumplimiento de su verdadera dignidad humana. El medio principal por el cual el gobernante cumplía su tarea era el convencimiento moral. No obstante que delegara la dirección de los asuntos diarios de rutina a sus funcionarios, era el responsable de dar ejemplo moral perfecto para los funcionarios mismos y su pueblo, de tal manera que todos fueran influidos por el poder de su bondad y arrastrados irresistiblemente a la práctica de la virtud. Con el objeto de alcanzar esa bondad y ser conocido por su pueblo, a esa bondad y virtud del gobernante se les daba una expresión concreta en los ritos y la música. Si la gente era expuesta a los influjos civilizadores de los ritos y la música, según insistían los intelectuales Han, no dejarían de ser educados y transformados. Esta era la idea del "gobierno por la bondad".

El concepto de la piedad filial, una virtud muy exaltada por los intelectuales confucianos, ocupaba una posición muy importante en la vida china a causa de sus efectos en el pensamiento y la práctica políticos. En la época Han se escribió un texto breve que se llamó el Clásico de la piedad filial, donde el autor atribuía a Confucio la expresión: "La piedad filial es la base de la virtud y 
la fuente del aprendizaje" (Wright, 1957: 76). Sólo después de aprender a servir con reverencia y obediencia a sus padres, uno podía cumplir sus otros deberes con el gobernante y la sociedad. En ese sentido la piedad filial tenía precedencia sobre todas las demás responsabilidades humanas, se convirtió en la piedra angular de toda la moral, y la obligación de amar y cuidar a los padres, de darles una sepultura correcta a su muerte y -elemento muy notable- reprimirlos suavemente pero con firmeza si se hubieran portado mal.

Los efectos políticos de esta doctrina fueron enormes en el periodo Han y en épocas posteriores. También tuvo grandes alcances la teoría de que las malas acciones del gobernante, o la falta de un buen gobierno en los niveles superiores, ocasionaban dislocaciones en el orden de la naturaleza y la aparición de cometas, eclipses, plagas de langostas, animales raros, etc. Tales fenómenos eran interpretados como manifestaciones directas del enojo del cielo y advertencias a la humanidad para reformarse. Esa corriente, llamada la "Teoría de los Portentos", registrada en la historia de la dinastía Han Antigua, tuvo una enorme influencia en el pensamiento político Han porque dio a la burocracia un método para censurar indirectamente al trono cuando la crítica directa no era políticamente correcta ni posible. En esa teoría se incluyeron los conceptos del "mandato del cielo" y del "derecho a la rebelión" o "teoría de la revolución”, que fueron elaborados por los mismos eruditos-funcionarios para aplicarlos según su criterio, práctica que alcanzó gran importancia posteriormente (De Bary et al., 1964: 170).

La importancia que tuvo este concepto es fácilmente imaginable, porque persistió íntimamente asociado al ejercicio del poder imperial hasta la época moderna y abarcó a Corea y Japón. Sin embargo, debe recordarse que los teóricos Han ofrecieron esta interpretación y justificación del poder imperial no para su propio beneficio, sino para restringir el abuso de su ejercicio al definir las grandes responsabilidades del gobierno imperial y al establecer instituciones que pudieran servir para controlarlo.

Con el paso del tiempo y de las dinastías, los principios confucianistas analizados y aplicados en el gobierno del imperio sufrieron cambios, readaptaciones y finalmente parecieron encaminarse a su desaparición, hasta que renacieron con el movimiento intelectual efectuado durante la dinastía Sung; luego fue interrumpido por el interludio de la dinastía Yüan (mongola), y se reanudó a la caída de ésta, con la dinastía Ming (1368- 
1644). Ese movimiento derivó en el neoconfucianismo, un confucianismo del que se eliminaron los elementos del budismo y el taoismo que se habían agregado con el paso del tiempo.

La renovación confucianista mantuvo su aplicación y práctica en el gobierno de la dinastía Ch'ing procedente de Manchuria (1644-1911), que conquistó China y sucedió a los Ming. Para gobernar aquel vasto imperio, los emperadores Ch'ing encontraron instalado un sistema filosófico que permitía controlar a la sociedad y el gobierno por medio de la red administrativa tejida y mantenida por los eruditos-funcionarios desde el palacio imperial y la capital de imperio hasta los rincones más apartados. Naturalmente, fue de su interés mantener el aparato estatal administrativo. Aún más que los mongoles de la dinastía Yüan, los manchúes gobernaron como emperadores chinos, mediante funcionarios chinos y con las instituciones chinas. Cada una de las oficinas y departamentos en la capital tenían una doble cabeza: un funcionario chino y uno manchú; también se conservó el código de leyes de los Ming. El neoconfucianismo de los Ming, apoyado en el pensamiento del filósofo Zhu Xi y sus interpretaciones, fue confirmado por el Estado Ch'ing como la fuente autorizada del aprendizaje y se perpetuó como la base de los exámenes del servicio civil. Esto propició un renacimiento vigoroso de los círculos intelectuales chinos, los cuales no dieron importancia alguna a las primeras ideas filosóficas y científicas de Occidente que habían llegado al imperio desde la época de los Ming por medio de los misioneros católicos europeos, en especial los jesuitas, quienes obtuvieron altas distinciones en la corte imperial por sus conocimientos astronómicos y de otras ciencias, no así por la religión que predicaban.

\section{Los principios normativos del mandarinato}

Los eruditos-funcionarios y su Estado encontraron en la doctrina de Confucio una ideología perfectamente adecuada. Antiguamente los ideales de los primeros miembros de la aristocracia feudal adoptaron esa ideología y formaron un nuevo estrato social de clases ilustradas revolucionarias, pero en la época de la unificación de la dinastía Han, siglo II a.C., en que se fundó el imperio, la ideología confucianista se convirtió en doctrina estatal. Cuando llegó el neoconfucianismo con la dinastía Ming, las virtudes que predicaba esa doctrina, que eran el respeto, la humildad, la docilidad, la obediencia, la sumisión y la subordina- 
ción a los mayores y superiores, a las que se agregó el culto a los antepasados y a la familia, venían muy bien para el nuevo Estado jerárquico. La prudencia, virtud cardinal para los eruditos-funcionarios, establecía que el nuevo confucianismo debía exaltar el carácter conformista y tradicional, pues una estricta adherencia a las doctrinas ortodoxas era la mejor defensa contra las presiones de grupos sociales.

Debe destacarse que la continuidad del confucianismo dependía por completo de la existencia prolongada del Estado centralizado, jerárquico y burocrático de los eruditos-funcionarios. Cada vez que ese Estado era acosado y los eruditos-funcionarios tenían que ceder su importante lugar a otros actores (nunca por mucho tiempo), los confucianistas se retiraban en silencio a lugares solitarios o poco importantes, para preparar ahí su retorno triunfal. Una de las razones por las cuales la sociedad burocrática perduró tanto tiempo en China fue por su capacidad para sobrevivir, la riqueza de su experiencia y éxito en el arte de gobernar. Si bien esa clase constituyó también una fuente de sufrimientos innumerables, sirvió a un propósito necesario. Fue el precio pagado por la homogeneidad, la gran durabilidad y la vitalidad de la civilización china. Si no hubiera sido por los eruditosfuncionarios que mantenían en orden a los señores feudales y terratenientes, al tiempo que ejercían un control férreo sobre la unidad del imperio, el particularismo hubiera terminado con la soberanía, y la civilización china hubiera perecido. En la China campesina era una verdad absoluta que la alternativa al reinado de la burocracia era la anarquía.

El Estado de los eruditos-funcionarios era tan fuerte que la clase mercantil nunca se atrevió a desafiarlo plenamente a fin de obtener leyes, libertades y autonomía para sí. Los empresarios chinos preferían llegar a un acuerdo antes que pelear, preferían imitar antes que innovar, invertir dinero sin riesgos en la tierra antes que arriesgarse a colocarlo en empresas industriales. Por ello su ideal era transformarse en parte del Estado, tornarse en eruditos-funcionarios ellos mismos, o bien sus hijos o nietos, lo cual podía lograrse con pagar la educación que impartían preceptores particulares, eruditos que no eran funcionarios, o a través de la compra de puestos cuando se ponían en venta, o la obtención de un nombramiento para los hijos o los parientes que se hubieran educado adecuadamente.

La burocracia de los funcionarios oficiales que estaba a cargo de la construcción de las obras públicas administraba los ingre- 
sos y decidía sobre la guerra y la paz provenía de un sector de la población pequeño, pero educado, el cual estaba al frente de los asuntos públicos por medio del sistema de escritura ideográfica del idioma chino, hermosa estéticamente pero difícil. Puesto que llevaba muchos años de estudio dominar el idioma escrito y la numerosa literatura de los clásicos y sus comentarios, era lógico que sólo los hijos de familias ricas podían tener una educación clásica. De esa forma fueron los grandes terratenientes quienes educaron hijos eruditos y llegaron a ser funcionarios que gobernaban el imperio e invertían su riqueza, bien o mal habida, en adquirir tierras. Como resultado, el ideal de un hombre líder en la China antigua no era devenir en comerciante, vendedor, general o sacerdote, sino en terrateniente-erudito-funcionario.

La historiografía china es el monumento más grande que se ha levantado para glorificar una clase social determinada. Los eruditos-funcionarios escribían la historia para los eruditos-funcionarios, por lo tanto, los otros grupos sociales y sus actividades eran pasadas por alto o relegados a un papel secundario, meramente incidental.

La China antigua, llamada también China imperial, como muchos de los viejos imperios en la historia, funcionaba bajo un gobierno centralizado políticamente pero básicamente descentralizado en lo económico. En ese imperio toda actividad de mayor escala, fuera de naturaleza política, económica, militar o religiosa, era controlada por una burocracia oficial grande y numerosa. Ese Estado burocrático era predominantemente agrario, cuyo ingreso provenía de la producción agrícola de un campesinado analfabeta, aunque inteligente, que con frecuencia, además de producir sus alimentos, suministraba la mano de obra requerida para las obras públicas, tales como la Gran Muralla o el Gran Canal, o bien los soldados para los ejércitos encargados de la defensa o las conquistas.

La familia o el clan controlaban al individuo. Estaba sujeto a la familia, y la sociedad gobernaba su conducta por medio de principios éticos, más que por códigos legales. La supremacía de la ley y la libertad del individuo bajo la ley nunca fueron principios que tuvieran la importancia que se les dio en Occidente.

En uno de los libros clásicos del confucianismo, el de la Doctrina del significado (Chung Yung), había una sentencia que fue citada con frecuencia por generaciones de estadistas y funcionarios del imperio chino. Cuando el duque Ai preguntó sobre el gobierno, Confucio le contesto: "Cuando los hombres adecua- 
dos están disponibles, el gobierno florece. Cuando los hombres adecuados no están disponibles, el gobierno decae [...] la administración del gobierno depende de los hombres adecuados" (De Bary et al., 1964: 119). Ya fuera que enfrentaran los problemas rutinarios de la administración, o ante crisis serias en la vida del Estado, en la China antigua los pensadores políticos y los hombres prácticos de negocios estaban de acuerdo en que el remedio principal para los problemas del día era el reclutamiento de hombres de talento para el servicio del Estado. El cambio legal y el institucional, que tanto se ha buscado en la tradición política occidental como remedio para los males políticos, era secundario en la tradición china, esos conceptos venían detrás de la búsqueda de hombres de talento.

La idea de que el gobernante debía ser servido y asesorado por un grupo de consejeros prominentes por su integridad moral y su sabiduría tiene hondas raíces en la historia china. Se deriva aparentemente de la insistencia de Confucio en que la esencia del gobierno correcto es la guía moral, doctrina que fue transmitida a los hombres del primer imperio en los escritos de la escuela confucianista.

El punto principal de la filosofía del gobierno por la bondad (jen), en forma totalmente distinta de cualquier idea occidental, ponía el énfasis en la virtud que conlleva la conducta adecuada. Conducirse de acuerdo con las reglas de propiedad o li daba a uno influencia sobre el pueblo. "El pueblo es como la hierba, el gobernante como el viento, en la dirección en que el viento sopla, se inclina la hierba" (Wright, 1957: 70-71). La conducta apropiada daba poder al gobernante. Con base en esas ideas, los eruditos-funcionarios se convirtieron en parte esencial del gobierno con la competencia especial de mantener su conducta moral y en esa forma conservar para el emperador y para sí mismos el Mandato del Cielo. Al triunfar sobre otras escuelas de pensamiento, los confucianistas se convirtieron en intérpretes de li y con la teoría de los portentos daban explicaciones sobre los fenómenos naturales y las calamidades y de lo que implicaban según las acciones del gobernante, que podían ser censuradas o rechazadas según las doctrinas clásicas de las cuales ellos eran maestros.

Con ese poder los eruditos confucianistas se colocaron en la posición estratégica desde la cual podían influir toda política del gobierno. A cambio de mantenerse en esa posición, proveían al régimen con la sanción racional y ética necesaria para el ejercicio de su autoridad en una época en que la mayoría de los gober- 
nantes de imperios en otras partes se basaban principalmente sobre sanciones religiosas. Esto constituyó una gran invención política.

\section{El sistema de exámenes de ingreso al servicio civil}

Cuando la dinastía Han (206 a.C.-221 d.C.) empezó a reorganizar el imperio centralizado y burocrático que dejó la dinastía Chin (221-206 a.C.), las ideas confucianistas empezaron a influir en la política pública. Los primeros pasos fueron para organizar el reclutamiento de servidores civiles sobre la base del mérito; los nombramientos a puestos oficiales se dieron a 'hombres de talento' que fueron recomendados a la capital del imperio por iniciativa de funcionarios locales. Más tarde, se utilizaron los exámenes para completar las recomendaciones como una medida del talento. Fue durante la dinastía Han cuando se estableció la primera relación entre la carrera oficial y una educación en los clásicos confucianistas, cuando el gobierno principió a emplear graduados de la universidad nacional con un entrenamiento confucianista.

Dos siglos antes de Cristo, en la época de la consolidación de la dinastía Han, los gobernantes establecieron varios principios de gobierno: primero, la autoridad política en el Estado estaba centrada en un hombre situado en la cumbre de la pirámide social que gobernaba como emperador. Segundo, la autoridad del emperador en la conducción de la administración se ejercía en su nombre por sus ministros principales, que se ubicaban en la cima de una burocracia que tenía varios niveles, y eran responsables personalmente ante él por el éxito o fracaso de su administración. Tercero, esta burocracia se centraba en el gran palacio de la capital, donde el emperador ejercía el poder de nombramiento a los cargos. La tarea principal de la burocracia se convirtió en la selección de los servidores civiles con un ojo a mantener su poder y otro a la dinastía. Por esta razón, el nepotismo, los nombramientos de parientes, principalmente del lado materno, se convirtió en una práctica temprana. Cuarto, los primeros gobernantes Han desarrollaron la institución de la inspección que más tarde se transformó en el Ministerio de la Censura (una especie de Contraloría) por medio del cual un funcionario en las provincias era 'vigilado' por otro funcionario de rango menor, que se nombraba y se enviaba en forma independiente del funcionario que vigilaría y no era responsable por las acciones de su 
superior. Estaba ahí para ver y reportar a través de largos documentos que escribía para sus denuncias.

De las maneras mencionadas y de otras más, el problema de la administración imperial se convirtió en la selección y control de los burócratas. Así, China iba a la vanguardia del desarrollo de los principios básicos del gobierno burocrático. A saber, la utilización impersonal de poderes delegados específicamente en áreas de jurisdicción señaladas por medio de funcionarios asalariados que informaban regular y periódicamente de sus actos durante los periodos para los cuales habían sido nombrados. Por más de dos mil años este sistema de burocracia territorial podía verse materializado en la ciudad administrativa amurallada del hsien (distrito o condado).

Después de varios siglos de división interna, durante la dinastía Sui (589-618) y la dinastía T’ang (618-906), los gobernantes se dieron cuenta de que el entrenamiento y reclutamiento de un servicio civil centralizado era la mejor forma de vencer los poderes del regionalismo y la aristocracia hereditaria. Para entrenar a una élite de mérito, los T'ang organizaron un sistema regular de exámenes y empezaron a reclutar un considerable número de sus funcionarios entre los graduados. Las siguientes dinastías chinas más importantes, la Sung (960-1279), la Ming (1368-1644) así como la Ch’ing (manchú), ya asimilada a China (1644-1912), confiaron en gran medida en el sistema de exámenes públicos y competitivos para reclutar funcionarios para el Estado. Esta fue otra gran invención política.

Ya en la época Ming los exámenes que se presentaban en los tres niveles -la prefectura, la provincia y la capital- conducían a la obtención de grados sucesivos. En su mayor parte, sólo la obtención de un grado académico calificaba a un hombre para ingresar al mundo de los funcionarios. Desde dinastías anteriores se habían hecho muchos experimentos con el contenido de los exámenes. Durante la dinastía T’ang, por ejemplo, se otorgaban grados en alguna de las especialidades que se ofrecían, inclusive en los clásicos, letras, derecho y otras (Guerrero, 1998). Bajo los emperadores Ming, esa lista se redujo cuando la estandarización de los exámenes hizo que éstos fueran únicamente sobre los clásicos confucianistas y su interpretación ortodoxa, conforme la definió el filósofo Zhu Xi de la época Sung. Es decir, con esas medidas el sistema empezó a anquilosarse. Fue la época en que la filosofía confucianista quedó basada en forma definitiva en los libros antiguos, los clásicos chinos. Como puede suponerse, esos 
libros antiguos se transformaron en un canon cuyos textos fueron interpretados y reinterpretados a través de los siglos. En este proceso, textos posteriores que fueron escritos para ese propósito se añadieron al canon como los antiguos, en tanto que otros de mayor antigüedad fueron olvidados (De Bary et al., 1964: 434-440).

En ese canon se acumularon 13 textos clásicos cuyo orden se simplificó por los eruditos que siguieron, quienes seleccionaron los famosos Cuatro Libros: las Analectas de Confucio, el Libro de Mencio, la Doctrina del significado y el Gran aprendizaje, que fueron abreviados para que cualquier gentilhombre pudiera aprenderlos de memoria. Sobre esas obras clásicas versaban los exámenes de ingreso al servicio civil.

Después, refinado por las experiencias cambiantes y los gustos de las generaciones sucesivas, el sistema de exámenes se convirtió en uno de los adornos principales del Estado chino tradicional. Dentro del gobierno, los asuntos relacionados con el servicio civil, su reclutamiento y composición, el sistema de exámenes y su grado de adecuación estaban entre los problemas más estudiados y eran materia de acerbas discusiones. Entretanto los exámenes periódicos se convirtieron en grandes acontecimientos públicos de la vida política china. La figura del erudito pobre, en camino a la capital para presentarse a los exámenes, se convirtió en una imagen indispensable de las historias de ficción y dramas de la literatura china desde la dinastía Sung.

También en la época Sung el funcionario-erudito quedó firmemente establecido como el pináculo de la estructura social china; su carrera daba al hombre, como ninguna otra en China o en otras partes, acceso al poder, al prestigio y la riqueza simultáneamente. La aparición de esta aristocracia de mérito, o meritocracia, descargó a la dinastía, en forma definitiva, de su dependencia de una aristocracia hereditaria más antigua. Varios especialistas (Balazs, 1966) consideran que la aparición de esta élite nueva, los "eruditos-funcionarios", tuvo tanta importancia que puede considerarse como el principio de la historia moderna china.

La utilización regular de pruebas para reclutar funcionarios tuvo consecuencias duraderas para la cultura así como para la sociedad. Las tradiciones del pensamiento y educación chinos empezaron a ser conformados gradualmente por los estándares y prácticas del sistema de exámenes. Los arduos preparativos -que consumían mucho tiempo- para presentarlos hicieron que los aspirantes a un cargo llevaran una virtual 'vida de exámenes', que fue culpable de ahogar toda originalidad y alimentó la con- 
formidad. El énfasis estaba en memorizar los libros clásicos y sus comentarios. Cultivar una buena memoria y ejercitarla en las evaluaciones escritas era la meta. Así, la tradición dirigió las energías intelectuales de generaciones de chinos hacia la órbita del Estado.

Desde un principio, varios observadores occidentales que llegaron a China identificaron muy pronto al servicio civil como una de las características únicas del cuerpo político chino. Mateo Ricci, misionero jesuita, arquitecto y uno de los primeros cronistas de las misiones jesuitas en China, dejó una descripción admirable por sus detalles del contenido y procedimientos del sistema de exámenes (Gallagher, 1942). Más tarde, en el siglo XVII y particularmente en el XVIII, descripciones como la de Ricci sobre el servicio civil en China, reclutado con base en la virtud individual, suscitaron una cálida admiración entre los filósofos franceses de la época de la Ilustración. Voltaire, Turgot y muchos otros fijaron en sus escritos la imagen del servicio civil chino como una carrera abierta al talento y se sirvieron de esa información para atacar la fuerza de los privilegios hereditarios en la Europa de su tiempo. En verdad puede constatarse una notable similitud entre algunas ideas confucianistas y las que proponían algunos filósofos europeos de esa época (Creel, 1960: 254-278, y Kracke, 1964: 331-339). No fue la primera ni la última vez en que una verdad a medias sobre China reavivó los argumentos políticos en Occidente.

\section{1. ¿Los exámenes fueron una oportunidad abierta al talento personal?}

El estereotipo sobre la eficacia ejemplar del servicio civil chino permaneció vigente por mucho tiempo. Fue sólo a principios del siglo xx cuando se inició el estudio serio del sistema de exámenes y el grado en que en verdad era una 'carrera abierta al talento'. Para ese entonces los investigadores académicos occidentales tenían una tradición histórica más madura, así como los recursos que les ofrecían las nuevas ciencias sociales que los auxiliaron en el análisis de la información china. Al mismo tiempo, la temprana admiración de Occidente por todo lo que era chino dejó su lugar a una apreciación sobria, aun al punto de un cierto desdén por el tan admirado Estado chino y sus instituciones. Con el nuevo siglo los investigadores académicos chinos también empezaron a tener una nueva perspectiva sobre las instituciones 
de su Estado tradicional. La abolición del sistema de exámenes en 1905 y la desaparición del imperio siete años más tarde les trajo una libertad nueva para someter las instituciones tradicionales a un minucioso análisis crítico del porqué de la debilidad china frente a Occidente. Los elementos del pensamiento occidental que se introdujeron a China, en especial en los decenios 10 y 20 del siglo xx, aportaron posiciones ideológicas nuevas a partir de las cuales fue posible juzgar la pertinencia de los procedimientos tradicionales.

Con esa actitud mental más crítica, estudiosos occidentales y chinos empezaron por averiguar si los exámenes de ingreso al servicio civil habían provisto de tanta sangre nueva al mundo oficial como se había proclamado. Los primeros intentos por medir cuantitativamente el grado de movilidad que causaba el ingreso al servicio civil se llevaron a cabo a finales del siglo XIX. En un estudio pionero, el padre Étienne Zi examinó las raíces étnicas y sociales así como las carreras subsecuentes de unos 300 hombres que obtuvieron con distinción el grado académico más alto, el chin-shih. También investigó los antecedentes educativos y sociales de los funcionarios de mayor rango del imperio y encontró que entre los graduados más distinguidos los chinos eran más numerosos que los manchúes, pero eran éstos quienes ostentaban en mayor número las posiciones más altas del servicio civil. La conclusión del padre Zi fue que las raíces étnicas, es decir, ser manchú cuando gobernaba una dinastía manchú, significaba poseer una base más segura para acceder a las más altas posiciones del gobierno que una preparación intelectual y moral de excelencia, conforme lo demostraban los exámenes aprobados (Menzel, 1963: VIII-IX).

Mientras que las conclusiones del padre Zi reflejan las características especiales de la clase gobernante bajo el dominio de "una dinastía de conquista", es decir, no china, pues la dinastía Ch'ing procedía de Manchuria, la pregunta más general que se planteó, la de la movilidad social, presentó un reto para los investigadores académicos posteriores. Éstos examinaron la movilidad social, y en particular aquella para ingresar al servicio civil de todas las principales dinastías de los últimos mil años. Como el padre $\mathrm{Zi}$, otros investigadores analizaron los antecedentes sociales y las carreras de graduados y funcionarios gubernamentales para saber, de una vez por todas, si el servicio civil en realidad reclutaba 'hombres de talento' sin importar sus antecedentes sociales o si, después de todo, estaba dominado por un grupo 
relativamente pequeño de 'grandes familias' que ejercían el poder por largos periodos (Kracke, 1963: 1-8).

Distinguidos estudiosos del tema (Ping-ti Ho, 1963) investigaron los antecedentes sociales de los chin-shih que tuvieron éxito para determinar cuántos graduados procedían de familias de comuneros, que no tenían cargo alguno, y cuántos provenían de familias de funcionarios que tenían puestos de gobierno. El resultado de ese análisis los llevó a la conclusión de que hubo un alto número de comuneros que ingresaron al servicio civil a través del sistema de exámenes, lo que atestigua el verdadero índice de movilidad en la China tradicional (Ho, 1963: 28-33).

Otros estudiosos se han preocupado más por otros aspectos de los antecedentes sociales de los graduados. Por ejemplo, algunos se interesaron en comprobar la desigualdad relativa de oportunidades, que hacía más fácil que aprobaran los exámenes de ingreso al servicio civil los candidatos criados en las ciudades que los que vivían en el campo. Sin embargo, sospechaban que ser ricos, especialmente si la riqueza procedía de grandes propiedades de tierra de la que disponía una familia de campesinos, podía costear la educación de alguno de sus miembros que prometiera éxito en los exámenes.

Cuando se presentaban para las pruebas, a los candidatos chinos se les pedía que dieran información sobre los grados y puestos que hubieran tenido sus antepasados paternos, así como sus lugares de residencia. Esta información fue la que permitió investigar posteriormente los antecedentes sociales de los candidatos. No se les exigía dar información sobre el estado de las finanzas o la riqueza de su familia. Por esta razón no puede comprobarse con exactitud si la riqueza era un factor de movilidad. Nunca podrá saberse si fue la riqueza o el talento lo que permitió a ciertos hijos de campesinos ascender en la escala de los funcionarios de gobierno. Sin embargo, puede reconocerse que, en algunos periodos de la historia china, ser rico tenía alguna importancia en el reclutamiento para el servicio civil, pues cuando el gobierno vendía los grados o los nombramientos por dinero, la riqueza podía transformarse en la obtención de un rango oficial. Aun para aquellos que buscaron un cargo siguiendo el camino establecido de los exámenes, sin comprar un cargo, ser rico podía tener una importancia definitiva; sólo con abundantes medios económicos podía disponerse del tiempo libre necesario para emprender y continuar los estudios que sucedían a los exá- 
menes, pagar un tutor y, en casos excepcionales, 'comprar' a algunos funcionarios encargados de los exámenes.

Numerosos estudios empíricos (Hsü, 1963) no definen cuántos ingresaban al gobierno directamente, pero sí calculan la entrada en el grupo más general de los graduados entre los cuales se escogían a los funcionarios. Probablemente siempre eran más numerosos los graduados que las posiciones de gobierno disponibles. De hecho, sólo el grado más alto, el chin-shih, aseguraba al que lo recibía la obtención, casi automática, de un nombramiento oficial. Una persona que tuviera el grado intermedio de chü-jen podría ser empleada en los niveles más bajos de la escala oficial, pero no tenía la garantía. Quien obtenía el grado menor de sheng-yüan casi nunca lograba un cargo. Entrar en la burocracia oficial o al grupo de los graduados no era lo mismo. Sin embargo, había una relación entre los dos procesos, puesto que tener un grado era un requisito para obtener un cargo. Es más, aun los graduados del rango inferior que no tenían puestos oficiales con frecuencia fueron empleados en funciones cuasi gubernamentales, sobre todo en el nivel local. Los magistrados locales tuvieron siempre a su disposición un buen número de graduados o aspirantes del nivel inferior para encargarlos en tareas menores. El estudiante debía prestar toda su atención en cada caso a la naturaleza del grupo cuyos orígenes sociales estuvieran siendo examinados.

Había otros procedimientos para llegar a tener un nombramiento, atajos para alcanzar un cargo en combinación con los exámenes. Estudios han demostrado que privilegios hereditarios permitieron la entrada al gobierno de los hijos de funcionarios sin pasar por los exámenes (Ho, 1963: 28-33). En algunas épocas se usaron esos privilegios sin que ello quisiera decir que quienes fueron así reclutados carecieran de talento; por el contrario, los hijos de funcionarios tenían la oportunidad de aprender en casa muchas de las habilidades y puntos de vista que calificaban a un hombre para asumir un cargo. Contra todo lo que ese hecho hacía suponer, el servicio civil no se convirtió en coto exclusivo de las familias notables, pues en muchas ocasiones éstas no pudieron mantenerse en una posición prominente.

Los estudios sobre la movilidad de la élite china se llevaron a cabo cuando se establecieron las discusiones sobre la naturaleza de la sociedad tradicional de China, aun por académicos marxistas que intentaron usar sus herramientas para el análisis de clases, y por muchos años se enfrentaron al problema de la estrati- 
ficación de la China tradicional. El estudio del reclutamiento y la promoción en el servicio civil empezó como un ejercicio de historia social, sobre el número de gente y esquemas de la movilidad social. Tales investigaciones contribuyeron mucho a la comprensión de la historia política, puesto que los esquemas de movilidad no pueden entenderse totalmente fuera de su contexto político (Wittfogel, 1963).

El impulso principal sobre la visión del problema vino de algunos pioneros que hicieron amplias generalizaciones y especulaciones sobre la naturaleza del Estado chino. En el siglo xx, Max Weber llamó la atención sobre la cercana relación entre la aparición de un servicio civil reclutado sobre la base del mérito y la desaparición del feudalismo en China. Igualmente, vio una conexión entre la alta tasa de movilidad de los que entraban como de los que salían del servicio civil, por una parte, y por otra, en el fracaso de los funcionarios para constituir un contrapeso al absolutismo dinástico. El argumento de Weber es retomado por Karl A. Wittfogel en Oriental Despotism: en vez de instaurar una sociedad abierta, la alta movilidad social constituyó la base de un gobierno imperial despótico (Wittfogel, 1957).

Entre otros estudios sobre los aspectos políticos del reclutamiento, están los que demuestran cómo la manipulación de las cuotas regionales para el sistema de exámenes fue utilizada por la dinastía para alcanzar finalidades políticas (Kracke, 1963). Otros comprueban que el proceso del reclutamiento para entrar al servicio civil llegó a estar íntimamente relacionado con las luchas de poder de facciones de la corte. También se ha demostrado que los cambios trascendentes en el proceso de reclutamiento y, por lo tanto en la movilidad, pudieron coincidir con las crisis políticas más importantes en la duración de las dinastías, y se presume que había una relación entre el proceso del reclutamiento, la movilidad efectiva y el ciclo dinástico (Fairbank, 1996: 125-141).

Más tarde se estudiaron los procedimientos para reclutar hombres para el servicio civil en otro contexto, el de la historia de las ideas y los valores. El interés cambió de la procedencia social y el contexto político de los funcionarios, y empezó a inquirirse acerca del concepto del "talento" y la naturaleza de la educación que calificaba a un hombre para un cargo en la China tradicional. Algunos argumentos en esa línea fueron expuestos primero por Mateo Ricci en el siglo XVII. En una de sus observaciones más agudas, el gran misionero jesuita hacía notar: 
Es evidente para cualquiera que ninguno trabajaría para alcanzar perfeccionamiento en las matemáticas o en la medicina si tiene la mínima esperanza de alcanzar a sobresalir en el campo de la filosofía. El resultado es que apenas hay alguien que quiera dedicarse a esos estudios a menos que haya sido impedido en su propósito de alcanzar lo que se considera que son los estudios de mayor altura, ya sea por razones de asuntos familiares o por tener un talento mediocre. El estudio de las matemáticas y el de la medicina se tienen en baja estima, porque no se obtienen honores con ellos como en el caso de la filosofía, a la cual los estudiantes son atraídos con la esperanza de alcanzar la gloria y las recompensas que le acompañan. Esto se puede ver de inmediato en el interés que se tiene por el estudio de la filosofía moral. El hombre que es promovido a los grados más altos en ese campo, se llena de orgullo por el hecho de que, en verdad, alcanzó el pináculo de la felicidad china (Gallagher, 1942).

En el último tercio del siglo XIX, algunos chinos reconocían que el atraso de su país en tecnología se debía en parte a las tradiciones educativas e intelectuales que habían sido promovidas y perpetuadas con el sistema de exámenes, basado como estaba en el estudio de los clásicos de filosofía, literatura e historia de la tradición confucianista, con exclusión de la ciencia y la tecnología. El status y la importancia del técnico calificado al servicio del Estado se habían discutido siglos antes de que volvieran a traerlos a la discusión los promotores del 'autofortalecimiento' de finales del siglo XIX.

$\mathrm{Al}$ conocer el status de los artesanos y técnicos en el servicio civil de la dinastía Ming, se sabe mucho sobre los ideales educativos de ese tiempo, en particular sobre una especie de jerarquía de calificaciones en las que se consideraban el carácter, la habilidad intelectual y la destreza técnica en un orden descendente.

No se sabe con claridad acerca de la forma en que los chinos de la época Ming, o de cualquier otra dinastía, concebían la relación entre carácter y habilidad. Sin embargo, esa relación era crucial para trabajar en el servicio civil y en los procedimientos de reclutamiento. Todos estaban de acuerdo en que "carácter" e "integridad" eran la marca distintiva de un verdadero funcionario calificado. No obstante, en la práctica la habilidad con frecuencia se adoptaba como una medida para evaluar a un hombre y era, en todo caso, una forma de evaluarlo además del "carácter".

Si en la dinastía Ming podía tenerse éxito por una evaluación equilibrada del carácter y la habilidad intelectual, la tendencia en la mayoría de las dinastías para ser reclutados consistió en los atributos que pudieran medirse y cuantificarse tales como la inteligencia, la memoria y aun la facilidad para escribir y redactar; 
es decir, lo que podía verse en los exámenes del servicio civil, en lugar de evaluar la estatura moral, que era intangible. Fue precisamente la sustitución de los criterios tangibles, pero secundarios, en lugar de los intangibles lo que trajo muchas críticas al sistema chino de exámenes a través de los siglos. Esas críticas ponían en claro que para los chinos el problema fue más serio que para las escuelas occidentales: la cuestión de los exámenes de cursos objetivos contra los subjetivos. Los chinos estaban, de hecho, a la búsqueda de alguna señal externa de una gracia interior que calificara a un hombre para el liderazgo político. Por esa razón, estudiar el procedimiento del reclutamiento para el servicio civil chino es observar el juego de ideas e instituciones en un área crucial de la experiencia china.

Una sociedad confuciana era por necesidad una sociedad agraria; el comercio, la industria y el desarrollo económico, en cualquiera de sus formas, eran sus enemigos. La historia era vista como una secuencia cíclica de renovaciones y ajustes continuos dentro de un orden fundamentalmente estable en el cual no podía haber conflictos básicos. La meta de la armonía perfecta debía alcanzarse mediante la solución de los conflictos menores por medio del compromiso y la concesión. La élite estaba constituida por los letrados, guiaban la vida social y ayudaban a mantener su curso natural; ellos no forzaban, no creaban ni innovaban. No eran ni propagandistas fanáticos, organizadores políticos, aristócratas, sacerdotes, hombres ricos ni especialistas de nada. Eran los chün-tzu, hombres de una moral superior y una capacidad intelectual y entrenamiento especiales, eran humanistas y conservadores.

Un antropólogo chino los definía así: Un hombre que mira al mundo sólo a través de las relaciones humanas se inclina a ser conservador, porque en las relaciones humanas el fin que buscan es siempre un ajuste mutuo. Y un equilibrio justo sólo puede encontrarse en una relación estable e inmutable entre el hombre y la naturaleza (Chang, 1963). Por otra parte, desde un punto de vista puramente técnico, apenas si hay límites al control del hombre sobre la naturaleza. Al enfatizar el progreso técnico, se involucra en un conflicto donde el control del hombre sobre la naturaleza es cada vez más cambiante y eficiente. Sin embargo, esos cambios técnicos pueden llevar a un conflicto entre hombre y hombre. Los intelectuales chinos vieron al mundo en forma humanista. Faltos de conocimientos técnicos, no podían apreciar el 
progreso técnico, y no encontraron razón alguna para cambiar la relación interhumana.

El campesino ocupaba el lugar más importante en la sociedad de los conservadores chinos. Sabían lo que significaba decir que la agricultura era la base del Estado. Los problemas sustantivos de la agricultura, económicos y técnicos, eran la principal preocupación de todo estadista. El campesino chino se tenía por bueno de origen, no pecador. Por ello no estaba entre los conservadores chinos la preocupación de la educación masiva que había en el Occidente. La limitación confuciana sobre la educación era de carácter económico; los hijos de los campesinos debían seguir trabajando en los campos y ocasionalmente eran eximidos de ese trabajo si alguno poseía facultades especiales para el estudio. No se imaginaban siquiera que si el campesino aprendiera a leer corría el peligro de extraviarse con otras ideas, sino más bien que entendería mejor las enseñanzas de la educación confuciana y ayudaría a propagarla. Si era de habilidad superior, se esperaba confiadamente en que se convirtiera en un funcionario y no en un iconoclasta. En teoría, el segundo puesto más importante sobre la tierra, el de ser un erudito-funcionario, estaba siempre abierto para él y, por si acaso tuviera la capacidad individual necesaria, el trono mismo estaba disponible si el emperador en turno perdiera su derecho a reinar a causa de violar los principios de la moral racional sobre los que se basaba ese derecho.

\section{El neoconfucianismo y la última Restauración china}

El renacimiento neoconfucianista echó atrás la autosuficiencia cultural que alimentaban los eruditos, pues de ello dependía que su clase se mantuviera y sus servicios continuaran siendo indispensables para gobernar aquel vasto imperio. El conocimiento de los bárbaros occidentales no podía estar por encima del chino y no se necesitaban los elementos del conocimiento occidental que fueran en detrimento o en contra de las ideas y teorías consagradas en los libros de épocas anteriores. Una soberbia intelectual y un orgullo nacionalista desmedidos los hizo rechazar todo lo que llegaba de fuera y no los preparó, por ello, para enfrentar la amenaza occidental que se presentó en el sur, en Guandong (Cantón), en cuya vecindad los funcionarios autorizaron por primera vez a los portugueses para iniciar su modesto comercio. Años más tarde llegaron los comerciantes y los barcos ingleses con otras ideas sobre el comercio y nuevas exigencias. 
En la segunda mitad del siglo xix, China sufría el asedio de las potencias occidentales que, deslumbradas por la riqueza que obtendrían al entrar al inmenso mercado chino, trataron de abrir mediante negociaciones diplomáticas la puerta de entrada a su territorio. Cuando éstas fracasaron porque se enfrentaban básicamente dos concepciones del mundo y dos formas de gobierno distintas, ante la incomprensión mutua Occidente echó mano de la superioridad tecnológica para forzar la entrada. Sin hacer caso de la prohibición del gobierno chino de que sus ciudadanos cultivaran y consumieran opio, los comerciantes ingleses llevaron a China ese producto por ser el único que tenía demanda. Las plantaciones en que cultivaban la amapola y procesaban el opio estaban ubicadas en la colonia inglesa más próxima al imperio chino, la India. Como los funcionarios chinos no autorizaron la entrada del opio y destruyeron en una ocasión toda la carga que lo llevaba, Inglaterra encontró el motivo y pretexto para las llamadas Guerras del Opio; la primera se inició en Cantón en 1840, la segunda años después, en 1860, cuando las fuerzas armadas de Inglaterra llegaron hasta Pekín, la capital imperial, donde, al no encontrar al emperador que había huido con la corte a Jehol, hicieron grandes estragos y destruyeron, entre otros edificios, el hermoso Palacio de Verano.

En esa misma época el gobierno chino de la última dinastía que ocupó el trono del imperio, la dinastía Ch'ing, se enfrentaba a varias revueltas interiores, la más poderosa era la rebelión Taiping en cuya supresión empleaba todos sus recursos militares y funcionarios más capaces. China era atacada por dos frentes, en el interno por múltiples insurrecciones, y en el externo por las potencias occidentales que deseaban entrar en su enorme mercado. En el frente interno el gobierno logró vencer las rebeliones, incluso con cierta ayuda de las potencias occidentales; pero en el frente externo sus armas tradicionales fallaron. Ante esa situación, los funcionarios del gobierno chino echaron la culpa al abandono de las vías tradicionales, en especial a la falta de hombres capaces de gobernar y administrar al país, de que China se encontrara en tan preocupante situación.

En 1862, dos años después de la destrucción de la capital, habían pasado las Guerras del Opio y China había aceptado firmar tratados en condiciones desiguales con las potencias occidentales que, para asegurar sus intereses comerciales, empezaron a separar porciones del territorio chino con litoral al Pacífico, que llamaron "esferas de influencia". Los más capaces, distin- 
guidos y sagaces funcionarios del gobierno imperial y gobernadores de varias provincias decidieron recuperar las fuerzas y vigor del imperio, como lo había sido en el pasado, por medio de la restauración de las tradiciones antiguas. Se inició así el periodo conocido en la historia china como la Restauración T'ung-Chih, que duró hasta 1874.

Durante ese último intento por fortalecer a China en lo interno para hacer frente al asedio creciente de las potencias occidentales, el gobierno chino buscó un regreso al régimen concebido de acuerdo con la ética confuciana, a la reconstitución de una jerarquía ordenada de funcionarios bien adoctrinados y seleccionados a través del sistema de los exámenes de ingreso al servicio civil. En ese contexto, el término "civil” del gobierno significaba una autoridad no militar ni eclesiástica, porque el término en el idioma chino li-chi tenía un significado mucho más amplio; era el gobierno por la bondad. El gobierno li-chi, como cualquier otro sistema administrativo de alta complejidad, podía degenerar en una 'burocracia', pero en su mejor expresión concedió una gran importancia a la experiencia de la educación y la aptitud de comprensión del funcionario individual, quien se guiaba por amplios preceptos más que por leyes y reglamentos severos y apresurados. En verdad, uno de los blancos de ataque favoritos durante el periodo de la Restauración fue la cantidad de trámites burocráticos que se habían acumulado con el tiempo e impedían un gobierno civil verdadero. Un distinguido funcionario chino de la época, Hu Lin-i, por ejemplo, urgía a que se simplificaran los reglamentos existentes, así como el estilo documental en que estaban escritos, de tal manera que pudieran ser entendidos y aplicados con justicia y equidad, según lo dictaba el sentido común (Mien hui-pi i, citado en Wright, 1957).

\subsection{El último intento por volver al pasado}

Desde el punto de vista del confucianismo, los elementos esenciales de un gobierno estable y de la armonía social (con paz social), la teoría del gobierno por la bondad (jen), eran la habilidad y la integridad de los funcionarios, y esa manera de ver se reflejaba en los proverbios y los dichos populares, así como en los documentos formales. Para los funcionarios de la Restauración T'ung-Chih de la segunda mitad del siglo XIX (1862-1874), la tarea principal era localizar hombres con las habilidades propias más altas, entrenar sus mentes y moldear sus caracteres, 
nombrarlos para un cargo sobre la base del mérito y recompensar o castigar su conducta oficial en una forma efectiva. Un distinguido funcionario erudito de esa época, Tso Tsung-dang, escribió:

El caos en el imperio resulta del hecho de que el gobierno civil no está debidamente atendido. El que el gobierno no esté debidamente atendido es resultado del hecho de que no hay hombres dotados de habilidad en cargos oficiales; que los hombres de habilidades no estén en cargos gubernamentales resulta de que los corazones de los hombres no tengan rectitud; que los corazones de los hombres no sean rectos resulta del hecho de que no existe el aprendizaje (Wright, 1957: 68).

Las habilidades de los funcionarios se consideraban relacionadas muy de cerca con las cualidades morales. Nadie podía sugerir impunemente que un hombre de moralidad superior pudiera ser incompetente en un cargo, o que uno moralmente inferior pudiera poseer grandes habilidades. Los estadistas de la Restauración estaban obsesionados con la idea del 'talento humano', obsesión que se reflejaba en el siguiente aforismo: "La conducción de la guerra está en los hombres, no en las armas", idea que siempre estuvo presente en las discusiones militares más técnicas. Un funcionario menor de la Restauración observó: "Cuando surgen circunstancias extraordinarias, debemos confiar en hombres extraordinarios y esos hombres extraordinarios llevarán a cabo cosas extraordinarias" (Wright, 1957: 69).

En 1860 quienes lograron suprimir la rebelión interna y restaurar el Estado chino no eran militares en el sentido occidental del término. En su mayor parte eran funcionarios, producto del sistema de exámenes, que habían alcanzado notabilidad porque habían probado poseer habilidades tanto en los asuntos civiles como en los militares. Durante la desmoralización y el caos del periodo anterior, el sistema tradicional para escoger a los funcionarios, el sistema de exámenes, había perdido mucho de su efectividad. Como resultado, muchos funcionarios que no cumplían con los requisitos tradicionales ocupaban los rangos menores de la burocracia. Los funcionarios de la Restauración se dieron cuenta de que sus políticas no tendrían efectos a menos que se mejorara la calidad de los funcionarios jóvenes y que, si no se detenía ese mal, los funcionarios menores sin formación adecuada constituirían la burocracia más alta del futuro. Urgía, por lo tanto, echar fuera a los funcionarios que habían obtenido sus cargos por procedimientos irregulares y resaltar los exámenes como 
el camino correcto para alcanzar las posiciones altas. Sin embargo, el sistema de la recomendación, por el cual un funcionario prominente patrocinaba la carrera de un joven que prometía, se convirtió en el corolario esencial del sistema de exámenes.

Aun cuando el mito chino de la movilidad social efectiva y del gobierno de los más habilidosos y virtuosos nunca se comprobó con la realidad histórica, el sistema de exámenes en su mejor expresión fue una institución notable establecida para hacer realidad un ideal. La Restauración Dung Zi (T’ung Chi) significó la resurrección del mito y de la institución. El sistema de exámenes con su extensa ramificación sirvió al Estado confuciano de tres maneras: a) produjo funcionarios inteligentes que fueron profundamente adoctrinados en la ética confuciana. Sin duda suprimió el pensamiento creativo, pero tampoco recargó a la burocracia con incompetentes. $b$ ) Mantuvo fija la atención de la clase superior en la ortodoxia y constituyó una salida para el talento y la ambición. c) Se ganó el apoyo popular al dar al pueblo funcionarios cuyo poder y comportamiento se basaba en los cánones aceptados universalmente, más que en la riqueza, el nacimiento, el poder militar o el capricho imperial.

Se calcula que en la época de la Restauración dos millones de candidatos se presentaban a los exámenes de uno u otro nivel, de los cuales solamente 1 o 2\% lograba tener éxito (Wright, 1957: 82). En los exámenes de distrito anuales se escogía a 20 o más candidatos entre los aproximadamente dos mil que competían en promedio. En los exámenes trienales para el grado provincial se seleccionaba a 100 de entre 10 mil solicitantes en promedio de cada provincia. Los graduados de las provincias competían en los exámenes trienales en Pekín para el grado metropolitano, de los cuales aproximadamente un tercio tenía éxito. Entre dos y 300 de aquellos que pasaban los exámenes metropolitanos competían en los exámenes de palacio, presentados en el palacio imperial, para obtener los honores más altos, incluyendo el título de primer erudito del imperio (chuang-yüan). Cuando había un candidato sobresaliente, los exámenes se realizaban en presencia del emperador (Wright, 1957: 82-83).

Había cuotas estatutarias de graduados para las provincias, que eran un medio de recompensar las contribuciones militares o financieras, sin debilitar el sistema de exámenes; aun se asignaron cuotas de graduados para recompensar a comerciantes o a miembros de la burguesía por sus contribuciones en dinero u otra forma para suprimir una rebelión. Esta especie de premio 
para la fortaleza militar o financiera de un área dada fue contraproducente porque se comprobó el peligro de bajar los estándares para adecuarlos a las capacidades de estudiantes mediocres.

Los propósitos de la Restauración eran no sólo exaltar los exámenes como el único camino al prestigio y el poder, sino también aumentar su utilidad por medio de modificaciones al contenido. Debía retornarse al sistema 'antiguo' con su énfasis en problemas sustantivos de la historia y la sociedad. En 1862 mediante un edicto se especificaron los temas fundamentales que debían contestarse y comentarse en los exámenes: primero, la conducta correcta, con base en los Cuatro Libros; segundo, las verdades morales fundamentales con base en los Cinco Clásicos; tercero, la política, conforme a las lecciones de la historia antigua y moderna; pero no desaparecieron del todo los temas sobre gobierno y filosofía. En los exámenes trienales de Wuchang en 1867 y 1870 , los temas fueron los clásicos, historia, geografía y problemas administrativos de entonces. Se premiaba el conocimiento de los hechos más que el análisis o juicios (Wright, 1957: 82).

Cuando en 1868 Ting Jih-zang, comisionado de Finanzas de Kiangsu, dispuso que se elaborara un examen especial destinado a echar fuera a los incapaces de entre los muchos que habían comprado un rango y que estaban en espera de los nombramientos a cargos, las preguntas planteadas se referían a problemas administrativos corrientes. Por ejemplo, en la segunda sesión fueron dos las preguntas: ¿Qué plan propondría usted para prevenir las irregularidades que existen entre los subalternos de los ministerios? ¿Qué medidas propondría usted para asegurar que los "voluntarios bravos" se asienten como súbditos pacíficos cuando sus servicios militares ya no sean necesarios? En la tercera sesión las dos preguntas fueron: Son numerosos los candidatos para los nombramientos oficiales y pocos los cargos disponibles. ¿Cómo podría usted resolver esta dificultad? Funcionarios menores se ocupan de juzgar casos que deberían ser remitidos a los magistrados del condado. ¿Cómo podría usted remediar este vicio? Presentados con el más estricto control a cargo del alto funcionario que había propuesto ese examen, muy pocos de los que habían comprado un rango pudieron aprobarlo (Wright, 1957: 83).

Las rebeliones fueron derrotadas, pero no podía repararse el daño que habían causado al sistema de los exámenes. Entre tanto el contacto con Occidente crecía y hacía que empezaran a aparecer dudas sobre la importancia del aprendizaje tradicional frente a los nuevos problemas. Cuando en 1866 no se presentó 
un solo candidato para obtener el grado preliminar en el distrito que incluía a Shanghai, se hizo evidente que empezaba a surgir una sociedad híbrida en los puertos abiertos a los extranjeros y en las áreas costaneras, una sociedad en la que el poder y la posición ya no estaban únicamente en manos de los letrados. Un periódico local, el North China Herald, comentó: "Es así como hemos socavado los fundamentos mismos del sistema político chino" (Wright, 1957: 84-85).

Con ese tipo de evidencias, se dijo en ocasiones que a partir de los inicios del siglo xIX en adelante los exámenes, así como el Estado al que servían, declinaron gradualmente. Por ello, los esfuerzos que se hicieron en la Restauración para retardar ese declinar y revitalizar el sistema tradicional fueron más conspicuos y exitosos de lo que generalmente se supuso. Paradójicamente los mismos letrados conservadores pusieron los obstáculos más serios para que esos esfuerzos tuvieran éxito.

La "venta de rangos" o "venta de oficios", que consistía en otorgar un rango oficial a los que contribuían a los fondos públicos, ya existía desde muy antiguo (la dinastía Ch'in), pero la persistencia del sistema de contribuciones llegó a su máximo uso durante la dinastía Ch'ing (manchú). Aun cuando el país en general había sido próspero hasta finales del siglo XVIII, en adelante se necesitaron fondos extras para hacer frente a las crisis. Solicitar contribuciones especiales se consideró siempre como una medida de emergencia para gastos militares, el control de ríos o para ayuda en los casos de desastres naturales. Un cargo no se ofrecía directamente en venta. Sin embargo, los compradores de rangos se convertían en elegibles para un cargo, y de hecho cada vez más se otorgaban nombramientos para puestos menores en el servicio civil. En la Restauración la abolición de la venta de rangos se convirtió en un punto básico.

La teoría política tradicional indicaba que la garantía principal de un buen gobierno residía, en primer lugar, en el entrenamiento y elección adecuada de los funcionarios; se reconocía que ellos, sin importar cuán bien habían sido seleccionados, debían ser 'motivados' mediante un sistema de recompensas y castigos. Los funcionarios ya en cargos eran examinados a intervalos regulares y sus actividades estaban sujetas a un escrutinio constante y a frecuentes denuncias de sus colegas. El Ministerio de la Censura estaba a cargo de la red de vigilancia, pero había también verificaciones internas a través de toda la jerarquía administrativa. Había investigaciones casi a diario sobre la compe- 
tencia de los funcionarios oficiales, así como informes cada tres años sobre sus méritos y fallas en toda la jerarquía. El North China Herald hacía notar:

[...] los principios del gobierno chino se ponen en práctica por medio de una graduación exacta y ordenada del rango, y cada servidor público está tan enteramente bajo el control del funcionario que está arriba de él, que no es fácil que se escape de ser detectado un sinvergüenza. A pesar de los abusos que existen, el sistema abarca los intereses de tantos que tiene una gran fuerza conservadora. Es como una red que se extendiera sobre todo el rostro de la sociedad, cada individuo aislado en su propio lugar y conectado mediante la responsabilidad con todos los que le rodean (Wright, 1957: 87).

Por disposición imperial, cada gobernador general de una provincia informaba y presentaba sus recomendaciones en un memorial, con base en el cual, si era aprobado por la Oficina del Servicio Civil, se emitía un decreto para hacerlas efectivas. Según el caso, el decreto podía ser llevado hasta la atención del emperador para su confirmación. Los funcionarios menores eran los más frecuentemente denunciados o despedidos, acusados de negligencia de acciones contra los que infringían la ley, por edad avanzada, por tener una baja inteligencia, sordera u otros impedimentos físicos, frivolidad, habla inadecuada y mal carácter. Los cargos que se hacían contra funcionarios mayores eran más serios. En un caso el funcionario a cargo de las relaciones exteriores de Shanghai fue acusado por el censor de atención insuficiente a los asuntos militares, tener intereses en una librería y en una casa de cambio y por despertar la animadversión popular. Se investigaron las acusaciones y el funcionario fue depuesto y transferido, pero también porque se necesitaba el lugar para otro que merecía esa posición.

El éxito o fracaso de la Restauración dependía de la medida en la cual pudiera reintegrarse la sociedad tradicional al nivel local sin detrimento de los nuevos planes del gobierno para alcanzar una modernización limitada en los campos de la guerra y la diplomacia. Dadas las características del control local en la China tradicional, alcanzar algún compromiso para que hubiera esa modernización limitada enfrentaba dificultades de fondo.

Las instituciones organizadas para el control local existían, pero su efectividad dependía en gran medida del poder de la persuasión. La burocracia civil no era tan numerosa como para salvaguardar el orden sin el consentimiento de la gente, pues no se mantenían fuerzas armadas para ese propósito, y las que había 
estaban asentadas en lugares muy distantes entre sí para otros fines. El control directo de la gente iba en contra de la teoría política ortodoxa. Un magistrado mantenía el control tradicionalmente con la ayuda de las fuerzas sociales locales, en especial con el uso de los eruditos del lugar, quienes constituían una especie de puente entre el magistrado y la gran masa de la población de su jurisdicción. Ese sistema de control local por medio de los eruditos fue fortaleciéndose desde que empezó la dinastía Ch'ing.

A mediados del siglo XIx los observadores extranjeros que viajaban por China se quedaban asombrados por la estabilidad de las comunidades locales, que aparentemente se autogobernaban sin que con ello socavaran la autoridad del centro. Thomas Wade, un diplomático inglés, hacía notar que "[...] el imperio Confucianista, de entre todos los imperios de la historia, no se basaba en el poderío militar, o en una religión, o en la superstición. Por todas partes era visible una gran organización y arreglo" (Wright, 1957: 40 y 263-265). La causa de esa aparente armonía era la aceptación universal de la ideología confucianista. Toda persona, entrañando al emperador, y todo grupo, incluso el gobierno central, se esforzaban por desempeñar el papel confucianista que les correspondía. Esa ideología venerable, armonizadora, moderada y a la vez autoritaria y centrada en la sociedad estaba casi perfectamente ajustada para mantener el control central en ese vasto y físicamente descentralizado imperio. Cuando el sistema funcionaba, los letrados aceptaban su papel junto con los privilegios y responsabilidades que les daba. No intentaban controlar el poder político para su provecho, sino que se esforzaban por avanzar en el conjunto de principios éticos que debían restringir la fuerza del poder político. El campesino también era adoctrinado para reconocer su lugar en el esquema total.

El control a través de la persuasión era el suplemento del control mediante una red de responsabilidad colectiva y de un sistema legal altamente desarrollado. En cualquier tipo de control la calidad del funcionario local era de primera importancia. Debía ser no sólo un administrador competente en todos los aspectos, sino que debía encarnar la enseñanza confuciana que era la sanción última de la autoridad. Cuando a mediados del siglo XIX las rebeliones internas y la presión extranjera habían resquebrajado la calidad del servicio civil confucianista, amenazaban los intereses de los letrados y propiciaban dudas entre la población sobre la buena fe del gobierno y de la validez del ideal tradicional, los 
estadistas de la Restauración consideraban que era su deber reconstruir la antigua sociedad sobre lo que quedaba de sus cimientos. Debía empezarse por reconstruir el servicio civil por medio del sistema de los exámenes. Urgía encontrar "hombres de talento" para adoctrinarlos debidamente y después designarles cargos de responsabilidad oficial y así reorganizar el gobierno hasta los rincones más lejanos.

La Restauración empezó un gran programa de reconstrucción de escuelas públicas, academias y bibliotecas, y rescató los libros que habían escapado de la destrucción de las rebeliones casi constantes. Los funcionarios provinciales recibieron órdenes para reconstruir las academias y devolverles sus dotaciones de tierras de cuyos productos vivían. Los semilleros para los futuros letrados debían ser instalados en las mejores condiciones, y los estudiantes cuidados, pues eran la base de la reforma de las costumbres, por lo cual debían estudiar los libros seleccionados en la forma correcta. Se reimprimieron los libros clásicos y las historias y se publicaron obras nuevas. Copias de libros antiguos que se habían perdido fueron adquiridas en Japón, donde por entonces importaban los que contenían las ideas y describían modos extranjeros que se favorecieron en la Restauración Meiji. Al tiempo que se trataba de revivir las bases y los libros en que se fundaba la doctrina confucianista y la sociedad tradicional, se extirpaban todas las ideas extranjeras, novelas, obras de teatro, frivolidades y todo tipo de 'literatura impura' en que se habían inspirado las rebeliones ya derrotadas.

El sistema confucianista de control por la persuasión se reforzó a través de varias organizaciones de grupo destinadas a: 1) asegurar la conformidad; 2) ser el canal directo por medio del cual el Estado podía disponer de alimentos y mano de obra de cada poblado. El instrumento más importante era el sistema pao-chia de responsabilidad colectiva y su corolario, el sistema li-chia de recaudación de impuestos. En cada área administrativa se guardaban registros públicos sobre los censos de población. Diez familias constituían un p’ai, cien familias un chia y mil familias un pao, y todos los miembros eran responsables de las acciones de los otros. Aun cuando las familias que constituían una unidad nombraban a quien era su cabeza, esa elección era confirmada por el magistrado, y los funcionarios del pao-chia actuaban al gusto del magistrado. El sistema militar era una institución local relacionada muy de cerca con el pao-chia, y operaba por medio de los mismos canales. Su función era proteger la región contra los mero- 
deadores de afuera, así como el pao-chia estaba diseñado para echar fuera del poblado a los malhechores. Ambos se complementaban para resguardar la seguridad y la armonía social. Sistemas como estos eran evidentemente necesarios en la administración de un Estado agrario centralizado.

Durante más de dos mil años China no fue un Estado feudal, sino un imperio dividido en distritos administrativos. Cada uno de los poderes totales estaba en manos de un hombre nombrado por el gobierno central y responsable ante él. Mantenía relaciones con los letrados, apoyaba los estudios y el aprendizaje, tenía a su cargo las operaciones de bienestar y rescate, controlaba las operaciones del pao-chia e interpretaba y aplicaba la ley. Desde el punto de vista chino, cuando el funcionario local era un hombre capaz, las distintas instituciones de control local eran efectivas; cuando el funcionario era incompetente, eran inútiles: los letrados estaban en su contra, los estudios eran una farsa, las obras de caridad o auxilio estaban mal administradas, el sistema pao-chia explotaba a la gente de mala manera y no podía hacerse valer la ley. Por ello los altos funcionarios enviaban memoriales al trono imperial sobre la importancia de nombrar al hombre indicado para un cargo local. Escribían entonces:

Si encontramos a los hombres debidos, hay control; si perdemos esos hombres hay caos. Esto ha sido la verdad desde los tiempos antiguos; hoy día es más urgente. El imperio es una acumulación de hsien (distritos). Si tenemos al hombre correcto para un hsien, un hsien estará bajo control; si logramos tener al hombre correcto en cada hsien, el imperio estará bajo control (Wright, 1957: 86).

Yen Ching-ming, gobernador de Shantung, envió un memorial donde decía: "Desde tiempos antiguos, sin una selección cuidadosa de funcionarios locales, nunca fue posible gobernar al imperio (Wright, 1957: 86).

Casi todos los memoriales enviados al trono urgían a que los funcionarios locales se nombraran solamente con base en el sistema de exámenes. Aun cuando todos los niveles de gobierno eran importantes, ninguno lo era tanto como el de la administración local. Los administradores locales eran más numerosos que sus superiores y trataban más directamente con el pueblo. Se recordaba con frecuencia entre los funcionarios que ni los letrados ni la gente común podían ser controlados a menos que el funcionario local estuviera compenetrado de la tradición confuciana. De este tenor eran todos los razonamientos de los altos 
funcionarios del gobierno central y de los gobernadores provinciales en la Restauración.

La Restauración fracasó, pero dejó muy claro que aun en las circunstancias más favorables no era posible que un Estado moderno pudiera ser injertado en una sociedad confucianista. No obstante, en los años subsecuentes las ideas políticas que se probaron, con todo y su grandeza, fueron halladas insuficientes. Derrotadas y decaídas fueron revividas por los líderes políticos que aun frente a la evidencia insistían en que la Restauración fue un éxito y que en su herencia está la llave del éxito para el control político en la China del siglo xx.

El imperio chino terminó con el triunfo de la Revolución de 1911, primero encabezada no por la figura principal que le dio una ideología y un proyecto, Sun Yat-sen, sino por el general Yüan Shih-kai, cuya efímera presidencia trató de cambiar al reclamar el trono vacante para una nueva dinastía de la cual él sería el primer emperador. A la muerte de Yüan, el doctor Sun fue proclamado presidente de la República China y su guía y programa político y social fue especificado en los cuatro documentos fundamentales que escribió: el plan para la reconstrucción nacional, los fundamentos de la reconstrucción nacional, los tres principios del pueblo y su Manifiesto fueron presentados a la Primera Convención Nacional de su partido, el Kuomintang.

Sun Yat-sen desconfiaba de los eruditos o intelectuales, quienes deslumbrados por la necesidad de los Manchú de gobernar el imperio por su medio, revivieron el sistema de los exámenes de ingreso al servicio civil y lo habían revisado para aceptar y conservar el gobierno de una dinastía extrajera, en vez de trabajar por la devolución del trono de los Ming, la última dinastía china. Confiaba más en las sociedades secretas, nacionalistas, que buscaban reivindicar el gobierno del imperio para los chinos (Sun, 1943).

A la muerte del doctor Sun, siguió como líder del Kuomintang y al frente del gobierno nacionalista de la República China un militar que había dirigido la academia militar de Whampoa, el general Chiang Kai-shek. Con ese nuevo gobierno, volvieron las ideas de revivir las bases que sostuvieron el imperio chino por miles de años; en especial, Chiang consideró necesario devolver a China su glorioso pasado y, entre otros aspectos, instituir un servicio civil según el modelo antiguo, de acuerdo con la filosofía confuciana, e inspirado por los estadistas y altos funcionarios 
chinos de la Restauración T'ung-Chih, la que, estaba convencido, había tenido éxito.

Después de que en 1915 Japón presentó sus Veintiuna Demandas al gobierno chino, las que levantaron un gran resentimiento contra aquel país, los sucesos en China se siguieron con gran rapidez y fueron los antecedentes del Movimiento del Cuatro de Mayo de 1919, en el que los estudiantes chinos encabezaron las protestas multitudinarias contra los resultados de la Conferencia de Paz de Versalles. La humillación de China inflamó a los nuevos líderes intelectuales que promovieron una campaña antijaponesa y un gran movimiento hacia la modernización para construir una nueva China por medio de reformas intelectuales y sociales. En particular aquellos líderes ponían el énfasis en las ideas occidentales sobre la ciencia y la democracia y atacaron fieramente la ética china antigua, las costumbres, literatura, historia, filosofía, religión y las instituciones políticas y sociales. Aquellas metas ganaron la simpatía de los nuevos comerciantes, industriales, trabajadores urbanos, con lo que el gobierno en Pekín tuvo que hacer compromisos en sus políticas interna y exterior. Los efectos de ese movimiento fueron lejos, fomentaron movimientos estudiantiles y obreros, fueron la causa de la reorganización del Kuomintang y del nacimiento del Partido Comunista Chino y, más tarde, de que se forjara la coalición de comunistas y nacionalistas con su centro en Cantón para rechazar la invasión japonesa.

En 1924, el primer congreso del Kuomintang, ya reorganizado, hizo una proclamación radical que fue la base del programa común con los comunistas. Para 1933-1934, las ideas de Chiang y sus lazos con los comunistas se deshicieron y, junto con su condenación por los comunistas chinos y los líderes de la Rebelión T’ai Ping del siglo XIx, proclamó su determinación por preservar la antigua moral y la sabiduría que les habían legado los antepasados. En 1928 Chiang pedía a sus funcionarios tener como lectura de descanso el estudio de los Cuatro Libros. En 1931 la fecha del nacimiento de Confucio se convirtió en una festividad nacional. Si originalmente los ideales del Kuomintang eran confusos y oscuros, para 1953, cuando ya estaba el gobierno nacionalista refugiado en Taipei, se pensaba que "los revolucionarios eran eruditos que tomaban como base de su preparación los estudios para estadistas (ching-shih) de la última época de la dinastía Ming y los primeros años de la dinastía Ch'ing, a los que habían añadido el pensamiento occidental" (Wright, 1957: 300-312). 
Los exámenes para ingresar al servicio civil se abolieron en 1905 , y si bien la ideología política y administrativa de Chiang evolucionó, no se encontró un sustituto efectivo para un nuevo sistema de reclutamiento de servidores públicos. Sin duda había jóvenes ambiciosos de los dos sexos que deseaban entrar a trabajar en el gobierno, y con frecuencia no pudieron hacerlo por los conductos normales ya dispuestos. En 1907 empezó a funcionar el nuevo sistema educativo y tomó varios años tener egresados capaces de incorporarse al servicio civil. Sin embargo, no hubo un regreso al antiguo sistema de exámenes hasta que las ideas de Chiang sobre el retorno a las tradiciones antiguas y a los ideales confucianos, como lo intentó y casi logró la Restauración T'ung Ch'ih, inspiraron al generalísimo y sus funcionarios a rehacer el anterior sistema de exámenes, pero las condiciones de la guerra continua, contra los comunistas primero y contra los japoneses después, no permitieron organizar el nuevo sistema. Realizarían ese proyecto después de 1949, cuando la República China se refugió en Taiwán.

No entraremos aquí a describir las políticas de la República Popular China, a partir de su nacimiento en octubre de 1949, sobre el tema del servicio civil, pero debemos recordar que una de las metas principales del pensamiento de Mao Tse-tung era erradicar totalmente las costumbres antiguas y la manera de pensar tradicional en China, para instaurar en su lugar un "hombre nuevo" que, libre de las ataduras de las filosofías y creencias del pasado, dedicara sus fuerzas a la construcción de la nueva sociedad china que pudiera llegar a su última etapa, el comunismo. Su frustración por no destruir totalmente las formas de pensar antiguas y poner en su lugar las que deseaba fue la causa principal de la Revolución Cultural que lanzó en 1957, así como las campañas continuas para no dejar que la inercia de las costumbres, los principios confucianos y la propia historia china volvieran a colocar una burocracia nociva, porque con ella en la administración pública, su ideal nunca se haría realidad.

La Revolución Cultural que inició Mao, incitada en especial contra los cuadros más altos del partido que se habían vuelto revisionistas, debía ser permanente para no dejar sedimentos ni intereses contrarios a su meta. Una burocracia que inevitablemente surgiría si no se mataba en sus raíces ahogaría su proyecto. En todo caso, el lugar de esa maquinaria de administración y gobierno capaz de llegar a todos los rincones del país sería el Partido Comunista Chino, que administraría por medio de sus 
cuadros formados para todos los niveles. Sin admitirlo abiertamente, como hizo Chiang en su momento, Mao volvió a utilizar el sistema pao-chia de responsabilidad colectiva, aquel espionaje mutuo y de supervisión de los cuadros del partido que se metía hasta en la vida íntima de los ciudadanos; volvió a instaurar aquella atmósfera de sumisión y miedo, como la hubo antes. Su muerte en 1976 abrió un nuevo capítulo en la historia de China. Una vez liquidada la Banda de los Cuatro y resuelta la lucha por el poder, se abrieron las ventanas a los nuevos aires que llegaron al interior y salieron del país, con el inicio de las Cuatro Modernizaciones en 1978, concebidas y promovidas por uno de los anteriores camaradas de armas y compañero de Mao desde los inicios de la lucha en Yenan, Deng Hsiao-ping, que impulsaron al país a una nueva etapa de la modernización de China y su reincorporación a la sociedad internacional. Para que entraran en vigor esas Cuatro Modernizaciones, el primer paso fue declarar liquidada la Revolución Cultural.

\section{Conclusiones}

La historia del servicio civil imperial de China pone de relieve, en múltiples pasajes, la importancia de la aportación cultural china a la concepción y desarrollo de las teorías sobre la administración pública de Occidente. La abolición del sistema de exámenes de ingreso al servicio civil imperial en 1905 no canceló la necesidad de contar con ese cuerpo profesional de administradores públicos indispensables para gobernar una nación de las dimensiones de China. Pasado el periodo de la revolución nacionalista de 1911, los ensayos frustrados de la república que encabezó Sun Yat-sen, en cuyo transcurso entraron a China las ideas que sustentaron la revolución bolchevique rusa de 1917, encontraron un terreno fértil para propagarse, dadas las condiciones internas del país. El expansionismo imperialista de Japón que llevó a la invasión del norte de China no hizo más que contribuir a la derrota de la República China y al triunfo del movimiento comunista que encabezaba Mao Tse-tung.

Cuando ese movimiento triunfó y el nuevo régimen de la República Popular China se enfrentó a los problemas de la organización, administración y control del enorme país y su población, tuvo que echar mano de muchos administradores anteriores que habían trabajado bajo la república y aun de algunos que fueron entrenados para el servicio civil imperial. 
Entre las múltiples acciones que debían iniciarse en el nuevo periodo estaba, desde luego, la que atañía a la reforma y constitución del servicio civil que el gobierno necesitaba. La política interior de China pasaba por múltiples acomodos y el gobierno sufría de una semiparálisis debida a los continuos cambios y altibajos de los funcionarios, desde los de más alto nivel, los principales cuadros del Partido Comunista, muchos de los cuales cayeron en desgracia en la Revolución Cultural y con la desaparición de la escena política de la Banda de los Cuatro. Con la resurrección política de Deng Hsiao-ping y la proclamación de las Cuatro Modernizaciones, fue evidente que se necesitaban profundas reformas en la administración pública. Se limpiaron todos los niveles, desde el gobierno central hasta los de las provincias, poblados y comunas, pues se necesitaba poner en los cargos principales a cuadros que hubieran entendido la importancia de modernizar a China para devolverla a la sociedad internacional.

En 1993 el Consejo de Estado aprobó un reglamento temporal para el servicio civil que ha venido aplicándose desde entonces; sin embargo, enfrentados a una corrupción rampante, altos funcionarios del gobierno, diputados del $10^{\circ}$ Congreso Popular Nacional, jueces y juristas actualmente están de acuerdo en que China tiene la necesidad urgente de contar con un servicio civil que aumente la eficiencia administrativa y termine con la corrupción. El 13 de marzo de 2003, el diario China Daily hizo diversas entrevistas a profesores universitarios y miembros del Congreso Popular Nacional sobre el tema del servicio civil, puesto que en la $10^{\text {a }}$ Sesión del Congreso se introdujo una iniciativa para una nueva ley del servicio civil. Un distinguido profesor de le Escuela de Gobierno de la Universidad de Pekín, Zhao Chenggen, advirtió que el servicio civil es una parte importante del sistema político de China, que los más de cuatro millones de servidores públicos constituyen una fuerza importante para iniciar políticas administrativas y que el manejo de esos servidores administrativos es un aspecto central del sistema político del país.

Una opinión similar expresó el profesor Ying Songnian, director del Programa de Derecho de la Escuela Nacional de Administración, quien subrayó que la calidad de los servidores civiles del país es de gran importancia para el desarrollo económico. El profesor Ying, quien es también diputado del $10^{\circ}$ Congreso Popular Nacional, junto con más de 90 de sus compañeros diputados miembros del cuerpo legislativo más alto del país, fueron 
quienes propusieron una nueva ley para el servicio civil durante la sesión anual del Congreso en 2003.

El profesor Yu An, que enseña derecho administrativo en la Escuela de Derecho de la Universidad Tsinghua, refiriéndose a esa nueva ley que se necesita, indica que debe servir para hacer el sistema del servicio civil más competitivo al seleccionar a los mejores aspirantes que sea posible.

De la misma opinión es el diputado Zhao Linzhong, representante de la provincia de Zhejiang, al este de China, quien añade que dicha ley debe centrarse en especial sobre el examen de ingreso al servicio civil. Zhao, egresado de la Universidad de Pekín, insiste en que el reclutamiento y la promoción de los servidores civiles son la clave del sistema.

Varios departamentos del Consejo de Estado iniciaron exámenes para reclutar servidores civiles en 1998, y la práctica se extendió a otras agencias del gobierno en todo el país en el año 2000. Al considerar esa situación, el profesor Zhao dijo que deben ponerse en práctica exámenes que sean estrictamente vigilados en todos los niveles de gobierno y que sean abiertos, iguales, competitivos y basados en calificaciones; hizo notar que en el pasado algunos funcionarios menospreciaron los resultados de los exámenes para favorecer sus propios criterios de selección. En su opinión, el contenido de los exámenes, en especial los escritos, era muy anticuado para permitir evaluar adecuadamente a un candidato y saber si estaba calificado para tener un puesto gubernamental. Agregó que los problemas más serios se prestan en las entrevistas con los candidatos, pues no tienen normas y estándares consistentes ni procedimientos específicos.

$\mathrm{Al}$ considerar y discutir la nueva ley, el profesor Zhao propuso que se vea que esa ley contenga requisitos legales claros para la organización de los exámenes, con principios y normas de procedimiento aplicables, y que permitan también evaluar a los candidatos para promociones y en esa forma poner fin a la corrupción que existe. Si no se dispone de un método científico, las promociones estarán influidas inevitablemente por los contactos personales más que por el desempeño en el trabajo.

Otro diputado, Gui Zhongyue, representante de la provincia de Shaanxi, situada al noroeste de China, propuso que se introdujera un sistema de evaluación por sorpresa, sin previo aviso, como una ayuda para identificar a los servidores públicos corruptos. Desde su punto de vista, el sistema administrativo de China, que aspira a apoyar el desarrollo de una economía de mercado, ya 
está maduro para aprobar una ley con todas esas características y requisitos.

No puede dejar de notarse que las opiniones expresadas por los entrevistados y sus propuestas son iguales a las que, en su día, expusieron los funcionarios del gobierno central y los gobernadores provinciales del gobierno imperial, en particular los de la Restauración T'ung Ch'ih de finales del siglo XIx. Son exactamente los mismos problemas a los que se enfrentan los administradores actuales de la República Popular China, como son también los mismos problemas a los que buscan solución las nuevas corrientes y teorías sobre la administración pública en todos los gobiernos, en especial inmersos como están en los problemas y oportunidades que trae la globalización.

Un aspecto central en el caso chino es lograr tener el mecanismo de control político y administrativo más efectivo para el nuevo modelo de desarrollo que adoptó. El socialismo de merca$d o$, el nuevo modelo chino, desató ya fuerzas internas que antes estuvieron controladas celosamente por los eruditos-funcionarios, en especial la fuerza que tienen las iniciativas económicas de los ciudadanos, que revelan cada día no solamente ingenuidad, inteligencia y ambición, sino la determinación de aprovechar las nuevas facilidades que dan los nuevos sistemas de comunicación, la electrónica más elaborada, para hacer negocios en el ámbito internacional, y ello conlleva, como lo temían los funcionarios chinos imperiales, abrir la puerta a ideas peligrosas para el sistema y apropiarse de la facultad de decidir por sí mismos lo que consideran más conveniente para ellos y sus familias.

La filosofía y principios del confucianismo se adaptaban perfectamente para gobernar una sociedad predominantemente agraria en la cual la obediencia y la lealtad eran las virtudes que sostenían la trama del imperio. En una sociedad que es crecientemente industrializada y vuelta hacia el comercio exterior, que ávidamente recibe la mayor inversión extranjera disponible en el mundo actual, aquellos principios ya no son aplicables, como tampoco lo es el antiguo sistema de reclutamiento de servidores públicos. La búsqueda de nuevos puntales para el socialismo de mercado y de administradores adecuados es continua, pero la 'puerta abierta', que no es igual a la política que proponía Estados Unidos desde mediados del siglo XIX, para entrar sin obstáculo alguno al enorme mercado chino se despejó para que los productos chinos salgan a los mercados mundiales en una oleada 
imparable que los inunda. Y una vez que se abrió esa puerta, ya no será posible cerrarla.

En China el impulso hacia la unidad política y el control central ocurrió desde muy temprano en su historia. A pesar de repetidos intentos de volver atrás, el movimiento hacia el establecimiento de un imperio persistió con un sentido de algo históricamente inevitable. El despotismo irresponsable a menudo fue moderado no por las unidades políticas inferiores, sino por las presiones sociales e intelectuales que se ejercían por medio de un sistema burocrático en continuo perfeccionamiento.

Ahora bien, el imperio chino desapareció, pero la República Popular China se enfrenta actualmente a problemas similares de corrupción entre sus funcionarios. En las circunstancias presentes de esa nación será muy interesante observar cuáles serán los principios sobre los que se constituirá el nuevo servicio civil chino, y cómo se seleccionará y entrenará a los funcionarios que necesita el gobierno chino en el siglo Xxi que, se dice, será el "siglo de Asia".

\section{Bibliografía}

Balazs, Etienne (1966), Civilización china y burocracia, Sur, Buenos Aires.

Chang, Chung-Li (1963), "Merit and Money”, en Johanna Margarete Menzel, The Chinese Civil Service. Career Open to Talent?, China Daily, Heath and Company, Boston.

Creel, Herrlee Glessner (1960), Confucius and the Chinese Way, Harper Torchbooks, Haper \& Row, Inc, Nueva York.

De Bary, William Theodore, Wing-Tsit Chan y Chester C. Tan (1964), Sources of Chinese Tradition, $3^{\text {a }}$ ed., vol. I, Columbia University Press, Nueva York.

Fairbank, John King (1996), China, una nueva historia, Andrés Bello, Santiago de Chile.

Gallagher, Louis (1942), China in the Sixteenth Century: The Journals of Matthew Ricci, 1538-1610, Random House, Nueva York. 
Guerrero, Omar (1998), El funcionario, el diplomático y el juez, Universidad de Guanajuato-Instituto de Administración Pública de Guanajuato-Instituto Nacional de Administración Pública-Plaza y Valdés Editores, México.

Ho, Ping-ti (1963), "Family vs. Merit in the Ming and Ch'ing Dynasties", en Johanna Margarete Menzel, The Chinese Civil Service. Career Open to Talent?, Heath and Company, Boston.

Hsü, Francis L. K. (1963), "Patterns of Downward Mobility", en Johanna Margarete Menzel, The Chinese Civil Service. Career Open to Talent?, Heath and Company, Boston.

Kracke, Edward A. (1963), "Region Family and Individual in the Examination System", en Johanna Margarete Menzel, The Chinese Civil Service. Career Open to Talent?, Heath and Company, Boston.

(1964), “The Chinese and the Art of Government", en Raymond Dawson, Delegacy of China, Oxford University Press, Londres-Nueva York.

Menzel, Johanna Margarete (1963), The Chinese Civil Service. Career Open to Talent?, Heath and Company, Boston.

Sun, Yat-sen (1943), San Min Chu I. The Three Principles of the People, Ministry of Information of the Republic of China, Chungking.

Wittfogel, Karl August (1957), Oriental Despotism. A Comparative Study of Total Power, Yale University Press, New Haven.

(1963), “The Hereditary Privilege vs. Merit”, en Johanna Margarete Menzel, The Chinese Civil Service. Career Open to Talent?, Heath and Company, Boston. 
Wright, Mary Clabaugh (1957), The Last Stand of Chinese Conservatism. The T'ung-Chih Restoration, 1862-1874, Stanford University Press, Stanford, California.

Recibido: 31 de enero de 2005. Reenviado: 24 de mayo de 2005. Aceptado: 1 de julio de 2005.

Omar Martínez Legorreta es coordinador del Programa Interdisciplinario de Estudios sobre Asia Pacífico y del Programa Interdisciplinario de Estudios sobre Las Américas, de El Colegio Mexiquense A.C., organismo del que fue fundador y primer presidente. Cursó la licenciatura en la Facultad de Ciencias Políticas y Sociales de la Universidad Nacional Autónoma de México, la maestría en la School of Advanced International Studies (SAIS), The Johns Hopkins University, Washington, DC, y estudios de doctorado en relaciones internacionales, en el área de especialización Este de Asia y Pacífico. De 1964 a 2000 fue profesor e investigador de tiempo completo en el Centro de Estudios de Asia y África de El Colegio de México, donde fungió también como secretario general (1967-1971), director del mencionado centro (1982-1985) y asesor de la Presidencia (1982-1985). Ha sido embajador de México ante la República Popular China (concurrentemente acreditado ante Vietnam del Norte, Vietnam del Sur y Kampuchea, 1975-1979) y en la República Socialista Federativa de Yugoslavia (concurrentemente acreditado ante Albania, 1979-1981); además, miembro de la delegación de México a la Conferencia General de la Unesco (París, 1974). Tiene una decena de artículos publicados en revistas nacionales e internacionales, orientados efectivamente a la zona Asia Pacífico. 